\title{
Household hazardous waste data for the UK by direct sampling
}

\author{
Rebecca J. Slack ${ }^{1}$, Michael Bonin ${ }^{1}$, Jan R. Gronow ${ }^{2 \dagger}$, Anton Van Santen ${ }^{3}$ \& Nick \\ Voulvoulis $^{1 *}$
}

${ }^{1}$ Centre for Environmental Policy, Imperial College, Prince Consort Road, London, SW7 2BP, UK

${ }^{2}$ Environment Agency, Block 1, Government Buildings, Burghill Road, Westbury-onTrym, Bristol, BS10 6BF, UK

${ }^{3}$ Waste Strategy Review, Department for Environment, Food \& Rural Affairs, Ashdown House, 123 Victoria Street, London, SW1E 6DE, UK

* To whom correspondence should be addressed. E-mail:

n.voulvoulis@imperial.ac.uk; Tel.+44 (0)207 594 7459; Fax. +44 (0)207 5946016.

\section{Tables SI-1 \& SI-2: Supporting Information}

\footnotetext{
${ }^{\dagger}$ Present Address: Centre for Environmental Policy, Imperial College London
} 
Table SI-1: Waste collected across the four collections, per waste sub-category, further to Table 2 ( $\mathrm{n}=465)$.

\begin{tabular}{|c|c|c|}
\hline Waste Category and Code* & $\begin{array}{l}\text { Initial collection } \\
\text { only /kg }\end{array}$ & $\begin{array}{l}\text { Final three } \\
\text { collections } / \mathrm{kg}\end{array}$ \\
\hline Primary cells - non-hazardous (A1.1) & 15.5 & 134.2 \\
\hline Primary cells - hazardous (A1.2) & 0.9 & 3.9 \\
\hline Secondary cells - non-hazardous (A2.1) & 1.5 & 4.2 \\
\hline Secondary cells - hazardous (A2.2) & 5.3 & 7.1 \\
\hline All batteries - A & 23.1 & 149.5 \\
\hline Water-based paint - non-hazardous (B1.1) & 85.6 & 314.6 \\
\hline Water-based paint - hazardous (B1.2) & 8.5 & 17.6 \\
\hline Solvent-based paint - (B2) & 97.9 & 235.1 \\
\hline DIY preparations - non-hazardous (B3.1) & 12.6 & 43.7 \\
\hline DIY preparations - hazardous (B3.2) & 29.9 & 72.7 \\
\hline Wood treatments - (B4) & 1.8 & 14.9 \\
\hline All paint and DIY waste - B & 236.3 & 698.6 \\
\hline Engine oil - C1 & 7.4 & 23.2 \\
\hline Greases/lubricants - C2 & 3.0 & 6.6 \\
\hline Antifreeze/coolant - C3 & 6.7 & 9.2 \\
\hline Brake fluid and similar - C4 & 2.4 & 1.9 \\
\hline Degreasers and similar - C5 & 0.4 & 2.8 \\
\hline Vehicle cleaners - non-hazardous (C6.1) & 1.9 & 3.3 \\
\hline Vehicle cleaners - hazardous (C6.2) & 4.8 & 10.9 \\
\hline All vehicle-related waste - $C$ & 26.6 & 58.0 \\
\hline Rodenticides - D1 & 0.5 & 0.4 \\
\hline
\end{tabular}


Table SI-1 (continued)

Waste Category and Code*

Initial collection Final three

only /kg
Molluscides - D2

Insecticides - D3

Herbicides - D4

Fungicides - D5

Combinations - D6

All pesticide waste - D

OTC $\ddagger$ - non-hazardous (F1.1)

OTC $\ddagger$ - hazardous (F1.2)

Prescription only - F2

Cytoxic or cytostatic - F3

All pet care waste - $\mathbf{F}$

All pharmaceutical waste - G

Developing fluid - H1

Fixer - H2

All photographic chemical waste - $\mathbf{H}$

Oven/ceramic cleaner - J1

Metal/wood cleaner - J2

Leather/suede cleaner - J3

All household cleaner waste - J

Ink jet - K1

Toner - K2

All printer inks/cartridges - K
6.3

3.1

0.8

16.7

0.02

1.8

0.05

0

1.9

0.4

1.5

0.2

1.6

1.3

3.0

1.5

7.5

1.3

1.9

10.7

12.5

1.1

0

10.0

1.1

* Hazardous unless otherwise stated 
Table SI-2: Mean quantity per household (kg or items) per waste sub-category over a 30-week period, further to Table 3. See Table 1 or SI-1 for the key to waste codes.

\section{Per household /kg or items (over 30 week period)}

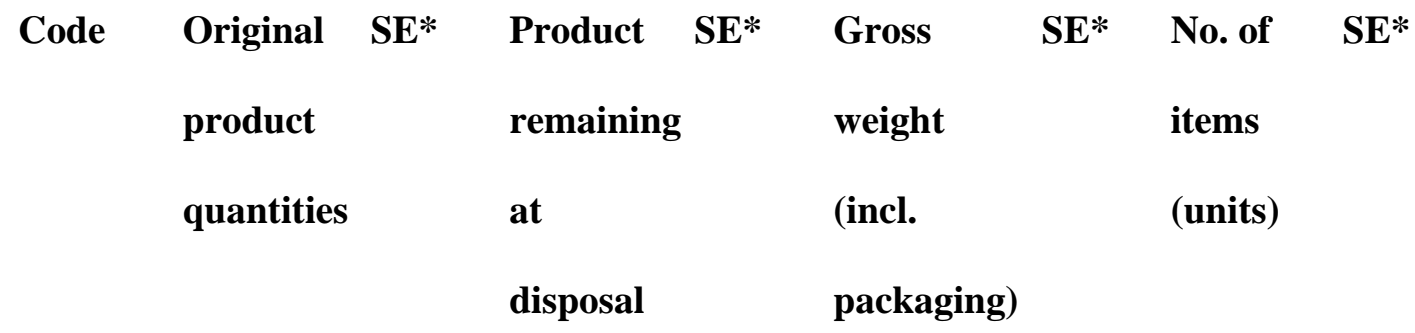

\begin{tabular}{|c|c|c|c|c|c|c|c|c|}
\hline$\overline{\mathrm{A} 1.1}$ & & & & & 0.289 & 0.010 & 9.327 & 0.314 \\
\hline A1.2 & & & & & 0.008 & 0.005 & 0.622 & 0.191 \\
\hline A2.1 & & & & & 0.009 & 0.001 & 0.267 & 0.165 \\
\hline A2.2 & & & & & 0.015 & 0.009 & 0.295 & 0.112 \\
\hline A & & & & & 0.322 & 0.026 & 10.51 & 0.721 \\
\hline B1.1 & 1.048 & 0.086 & 0.368 & 0.041 & 0.677 & 0.082 & & \\
\hline B1.2 & 0.039 & 0.032 & 0.029 & 0.022 & 0.038 & 0.013 & & \\
\hline B2 & 0.703 & 0.104 & 0.323 & 0.050 & 0.506 & 0.101 & & \\
\hline B3.1 & 0.134 & 0.048 & 0.071 & 0.029 & 0.094 & 0.032 & & \\
\hline B3.2 & 0.277 & 0.047 & 0.111 & 0.021 & 0.156 & 0.026 & & \\
\hline B4 & 0.084 & 0.011 & 0.026 & 0.012 & 0.032 & 0.005 & & \\
\hline B & 2.285 & 0.166 & 0.906 & 0.161 & 1.502 & 0.112 & & \\
\hline C1 & 0.103 & 0.079 & 0.036 & 0.014 & 0.050 & 0.041 & & \\
\hline C2 & 0.022 & 0.011 & 0.010 & 0.009 & 0.014 & 0.008 & & \\
\hline C3 & 0.034 & 0.025 & 0.017 & 0.013 & 0.020 & 0.015 & & \\
\hline C4 & 0.013 & 0.010 & 0.003 & 0.002 & 0.004 & 0.003 & & \\
\hline C5 & 0.010 & 0.009 & 0.003 & 0.001 & 0.006 & 0.001 & & \\
\hline C6.1 & 0.012 & 0.003 & 0.006 & 0.003 & 0.007 & 0.006 & & \\
\hline
\end{tabular}




\section{Per household /kg or items (over 30 week period)}

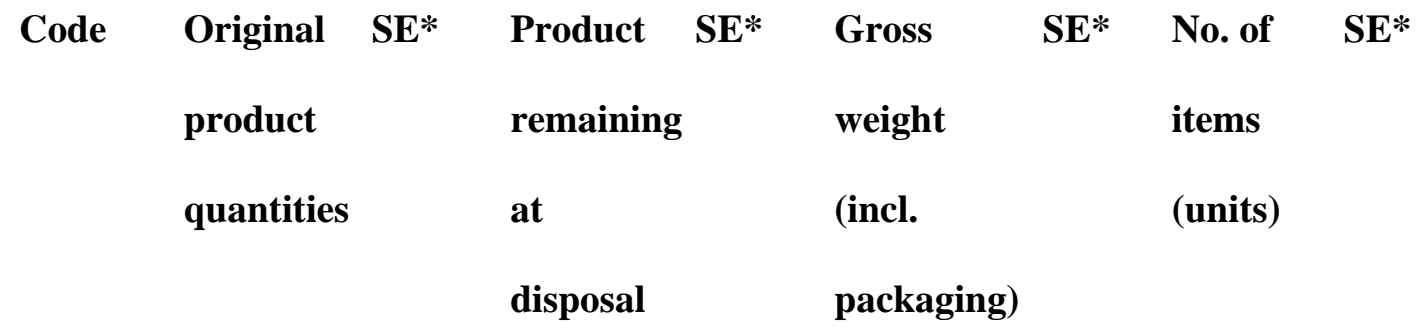

\begin{tabular}{|c|c|c|c|c|c|c|}
\hline C6.2 & 0.046 & 0.013 & 0.015 & 0.007 & 0.023 & 0.008 \\
\hline C & 0.240 & 0.073 & 0.089 & 0.004 & 0.125 & 0.016 \\
\hline D1 & 0.001 & 0.001 & 0.001 & 0.001 & 0.001 & 0.001 \\
\hline D2 & 0.007 & 0.003 & 0.005 & 0.004 & 0.006 & 0.002 \\
\hline D3 & 0.035 & 0.014 & 0.013 & 0.007 & 0.022 & 0.006 \\
\hline D4 & 0.062 & 0.055 & 0.034 & 0.028 & 0.040 & 0.024 \\
\hline D5 & 0.007 & 0.002 & 0.003 & 0.002 & 0.005 & 0.002 \\
\hline D6 & 0.004 & 0.002 & 0.001 & 0.001 & 0.001 & 0.001 \\
\hline D & 0.116 & 0.010 & 0.056 & 0.005 & 0.074 & 0.007 \\
\hline F1.1 & 0.001 & 0.001 & 0.000 & 0.000 & 0.000 & 0.000 \\
\hline F1.2 & 0.004 & 0.003 & 0.001 & 0.001 & 0.003 & 0.002 \\
\hline F2 & 0.002 & 0.001 & 0.001 & 0.000 & 0.001 & 0.000 \\
\hline F3 & 0.000 & 0.000 & 0.000 & 0.000 & 0.000 & 0.000 \\
\hline $\mathbf{F}$ & 0.007 & 0.003 & 0.002 & 0.001 & 0.005 & 0.002 \\
\hline G & 0.021 & 0.005 & 0.004 & 0.001 & & \\
\hline G1 & 0.011 & 0.003 & 0.003 & 0.001 & & \\
\hline G2 & 0.003 & 0.001 & 0.000 & 0.000 & & \\
\hline G3 & 0.001 & 0.000 & 0.000 & 0.000 & & \\
\hline G4 & 0.000 & 0.000 & 0.000 & 0.000 & & \\
\hline
\end{tabular}




\section{Per household /kg or items (over 30 week period)}

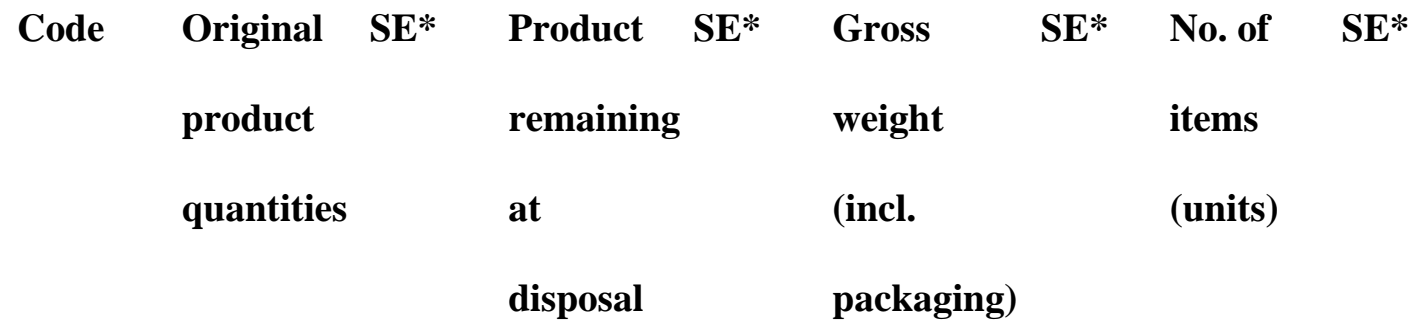

\begin{tabular}{|c|c|c|c|c|c|c|c|c|}
\hline G5 & 0.000 & 0.000 & 0.000 & 0.000 & & & & \\
\hline G6 & 0.000 & 0.000 & 0.000 & 0.000 & & & & \\
\hline G7 & 0.000 & 0.000 & 0.000 & 0.000 & & & & \\
\hline G8 & 0.003 & 0.001 & 0.000 & 0.000 & & & & \\
\hline G9 & 0.000 & 0.000 & 0.000 & 0.000 & & & & \\
\hline G10 & 0.003 & 0.001 & 0.000 & 0.000 & & & & \\
\hline G11 & 0.001 & 0.000 & 0.000 & 0.000 & & & & \\
\hline H1 & 0.001 & 0.001 & 0.000 & 0.000 & 0.000 & 0.000 & & \\
\hline H2 & 0.003 & 0.002 & 0.002 & 0.001 & 0.003 & 0.002 & & \\
\hline $\mathbf{H}$ & 0.004 & 0.002 & 0.002 & 0.001 & 0.003 & 0.002 & & \\
\hline $\mathrm{J} 1$ & 0.016 & 0.007 & 0.007 & 0.006 & 0.011 & 0.010 & & \\
\hline $\mathrm{J} 2$ & 0.011 & 0.006 & 0.006 & 0.005 & 0.008 & 0.006 & & \\
\hline J3 & 0.007 & 0.003 & 0.003 & 0.002 & 0.007 & 0.003 & & \\
\hline $\mathbf{J}$ & 0.034 & $\mathbf{0 . 0 0 7}$ & 0.016 & 0.007 & $\mathbf{0 . 0 2 7}$ & 0.010 & & \\
\hline K1 & & & & & 0.012 & 0.005 & 0.239 & 0.097 \\
\hline K2 & & & & & 0.022 & 0.014 & 0.017 & 0.001 \\
\hline $\mathbf{K}$ & & & & & 0.034 & 0.020 & 0.252 & 0.098 \\
\hline
\end{tabular}

* Standard error of the mean 